\title{
MENTAL HEALTH OF THE POPULATION AFFECTED AFTER NATURAL DISASTER OF 20 FEBRUARY 2010 IN MADEIRA AUTONOMOUS REGION
}

\author{
Jardim,Helena Gonçalves ${ }^{1}$, Silva,Rita ${ }^{2}$, Gouveia,Bruna Raquel ${ }^{3}$,Baptista, Márcia ${ }^{4}$,Nurses of Mental health \\ ${ }^{1} \mathrm{PhD}$, Coordinator Professor, Madeira University - Health Higher School \\ ${ }^{2} \mathrm{PhD}$, Head Nurse in the NélioMendonça Hospital - Funchal \\ ${ }^{3} \mathrm{PhD}$,Assistant Professor, Saint Joseph of Cluny Higher School of Nursing - Funchal \\ ${ }^{4} \mathrm{BSc}$, Matematics, Madeira University \\ ${ }^{5}$ Nurses of the specialization course in Mental Health Nursing and Psychiatry at the University of Madeira \\ Email: hjardim@staff.uma.pt \\ DOI: http://dx.doi.org/10.15520/ijnd.2017.vol7.iss01.194.23-25
}

\begin{abstract}
Natural disasters resulting from climate change have increased currently.More and more people feel unprotected without security and therefore vulnerable to stress and anxiety may cause lasting mental illness. Post-Traumatic Stress Disorder(PTSD), is an anxiety problem that develops in some people after extremely traumatic events, such as combat, crime, an accident or natural disaster.People with PTSD may relive the event via intrusive memories, flashbacks and nightmares; avoid anything that reminds them of the trauma; and have anxious feelings they didn't have before that are so intense their lives are disrupt (APA, 2013).Identifying the natural disaster of the 20th February 2010 in the Autonomous Region of Madeira as a potentially traumatic event, the objectives of this research were: (1) to describe the levels of PTSD and dissociative responses to exposure to peritraumatic experiences associated with alluvial the natural disaster of February 20, 2010, in a sample of adults living in the Autonomous Region of wood (RAM), namly in the districts of Funchal, Santa Cruz and Ribeira Brava; (2) to analyze the relationship between the district of residence and levels of PTSD and dissociative responses to exposure to peritraumatic experiences; and (3) to assess the rate of occurrence of PTSD in these individuals. This cross-sectional study included a sample of 602 adults living in the districts most affected like Funchal, Ribeira Brava and Santa Cruz. The instruments for assessing the individuals were the Peritraumatic Experiences Questionnaire (QEPT; Maia, Moreira \&Fernandes, 2009) and the Response Evaluation to Traumatic Event Scale (EARAT; McIntyre \& Ventura, 1996). The majority of the population was exposed to significant peritraumatic experiences $(85.4 \%)$ and about a quarter of the sample $(25.4 \%)$ had criteria for the diagnosis of PTSD. Between the subsamples defined by district in respect to the average scores of the QEPT and subscale EARAT - Long term Responses we verify the existence of statistically significant differences. Most individuals exposed to significant peritraumaticexperiences was found in the sub-sample of Santa Cruz (90.5\%) and the highest percentage of people diagnosed with PTSD was found in the sub-sample of Ribeira Brava $(32.6 \%)$ The scientific importance and the clinical relevance of these findings, envision their usefulness in understanding the impact of this natural disaster with a view to the promotion of mental health in the support to victims of disasters in Madeira.
\end{abstract}

Keywords:Natural Disasters, Peritraumatic Experiences, Post-traumatic Stress Disorder.

\section{INTRODUCTION}

The epidemiological investigation on exposure to potentially traumatic experiences in adults have found that these are common throughout the world (Galea, Nandi \&Vlahov, 2005), including accidents and disasters of human and natural causes and being associated with the incidence of PTSD (Neria, Nandi \&Galea, 2007).

The disturbance of PTSD (Post Traumatic Stress Disorder-PTSD) is an anxiety disorder, being encoded in different classifications of diseases (DSM IV and ICD-10). This psychiatric pathology is characterized by symptoms of intense fear, horror and despair, which develop after exposure to a traumatic event (APA, 2013). People with PTSD may relive the event via intrusive memories, flashbacks and nightmares; avoid anything that reminds them of the trauma; and have anxious feelings they didn't have before that are so intense their lives are disrupt (APA, 2013).

The discussion about the problem of PTSD was in the years 60 , in the United States of America, where several studies verified a high prevalence of this anxiety disorder on Veterans of the Vietnam war.Although, the clinical and scientific community were aware of this problem after the colonial war, in Portugal, the first epidemiological research in this area, in the adult population, was published in 2003 (Albuquerque et al., 2003). In this research, which consists of 2606 sample individuals, it was found that $75 \%$ of the population was exposed to at least a traumatic situation and the prevalence rate of PTSD was $7.9 \%$.Were identified several traumacausing experiences, in particular, the violent death of family member or friend, witness a serious accident or death, serious accident or a natural disaster.More recently, several studies have been conducted on this subject, analyzing the prevalence of PTSD in special populations, individuals exposed to traffic accidents and professional groups that work on emergency assistance (Maia et al., 2006; Maia et al., 2011; Pires\& Maia, 2004, 2006).In the international field studies describe the impact of natural disasters on the community (Neria, Nandi \&Galea, 2007), however, despite the common and recurring alluvia in RAM, of our knowledge, no research has assessed the impact of these potentially traumatic events in the 
population of Madeira, with regard to the development of PTSD.

\section{Goals}

Identifying the natural disaster which occurred in the Autonomous Region of Madeira in the day 20 February 2010 as a potentially traumatic event, is goal of this research: (1) describe the levels of levels of dissociative responses to exposure to experiences questionnaire and PTSD, associated with natural disaster of February 20 of 2010, on a sample of individuals resident in RAM, in particular in the municipalities of Funchal, Santa Cruz and Ribeira Brava; (2) analyze the relationship between the municipality of residence and levels of dissociative responses to exposure to experiences questionnaire and PTSD; e (3) assess the rate of occurrence of significant experiences questionnaire exposure and PTSD in these individuals resident in RAM.

\section{METHODS}

This cross-sectional study involved a stratified proportional sample of 602 adults (age 18 or more years) living in the three counties most affected by alluvial wood of February 20 2010, in particular, in the municipalities of Funchal and Ribeira Brava and Santa Cruz. Excluded individuals who provide cognitive deficit, evaluated through the advice as to the time, space and person, motor and neurological deficits, and psychopathologies that could compromise the participation.

In addition to this, we used the following assessment tools: the questionnaire of peritraumaticexperiences (QEPT; Maia, Moreira \&Fernandes, 2009) and the scale of assessment of response to traumatic event (EARAT; McIntyre \& Ventura, 1996). It was the auto completion of questionnaires preferred, however, they were used as a guide to structured interview, in front of individuals who were unable to read or write.

The informed consent was required before any participation, being guaranteed the anonymity and confidentiality of the data. This research was preceded by an appreciation and positive opinion of the Ethics Committee for the health of the Health Service of the RAM.The data collection was carried out between the end of 2012 and 2013. The statistical procedures included simple descriptive statistics and analysis of variance (ANOVA), using the statistical software SPSS, version 20.

\section{Presentation and Discussion of the results}

This study included a sample of 602 participantsresidents in the Autonomous Region of Madeira (RAM), in the municipalities of Funchal (58.1\%), Santa Cruz (26.1\%) and Ribeira Brava (15.8\%).

The average age of the individual respondents was 44 years and the standard deviation of \pm 15.2 years. In this sample, $55.1 \%$ of respondents were active, $10.5 \%$ occupied with housework, $9.6 \%$ were unemployed, $10.8 \%$ were retired, $6.8 \%$ were students and the remaining $7.1 \%$ had other types of occupation. $27.1 \%$ of respondents lived alone or accompanied by another person, $51.8 \%$ with household consisting of three or four people and $21.1 \%$ for five or more people.

With regard to the place where they were during the mudslide of February 20 2010, 71.8\% of the respondents in the sample reported meeting at his residence, $11.6 \%, 8.3 \%$ in traffic in the street and the remaining $8.1 \%$ were within other locations. $25.4 \%$ of respondents indicated that, whilst not being part of a professional body involved in providing relief, were involved in supporting the victims of this disaster.

In table 1 are presented the main results of this study, in particular as regards exposure to experiences questionnaire associated with alluvium of 20 February 2010 and the levels of symptomatology of PTSD, in total of respondents from the sample. Regarding exposure to traumatic events, although the average score in the QEPT for the total sample was low (26.07), it was possible to verify that $85.4 \%$ were exposed to significant experiences questionnaire associated with dissociative responses potentially predictive of PTSD (Maia, Moreira \&Fernandes, 2009). Checking the symptomatology of PTSD, the results show that despite the expression of these symptoms be reduced in the total sample (average score of 5.7), 25.4\% of the sample presents PTSD, taking into account the criteria for diagnosis of the DSM IV (APA, 1994) and the cutting point proposed by the author of the scale used.

Table 1 Results on the level of dissociative responses to exposure to experiences perytraumatic and symptomatology of PTSD, in the total sample.

Variables

Population $(\mathrm{n}=602)^{*}$

Exposure to experiences $26.07(10.91)$

perytraumatic(QEPT, score)

Symptomatology of PTSD (EARAT, score) 5.70 (4.72)

* The values correspond to the mean and standard deviation. Analysing subsamples characterized by the municipality of residence, whose results are expressed in table 2 , it is possible to check the scores of QEPT close, however there are statistical significance differences between groups. Having regard to thecutting point of QEPT point, identifying exposure to experiencesperi traumaticsignificant associated with dissociative responses, the largest exposure to this type of experiences happened in the sub-sample of Ribeira Brava (90.0\%), followed by the Funchal $(85.1 \%)$ and finally, the Santa Cruz $(82.8 \%)$.

Regarding the symptoms of PTSD, the average scores for the three EARAT sub-samples are close, if not checking statistical significance differences between the groups. An exception is encountered when you analyze the subscales comprising the EARAT.As regards the lengthy replies subscale, there are differences with statistical significance between the groups and the score is higher on the sub-sample of Ribeira Brava.

The results for the subsamples demonstrate that despite the expression of symptoms of PTSD be reduced (average score 26.59, 26.06, 23.11 to Funchal and Ribeira Brava and Santa Cruz, respectively), taking into account the criteria for diagnosis of the DSM IV (APA, 1994) and the cutting point proposed by the author of the scale used, the rate of occurrence of PTSD was 32.6\% in the sub-sample of RibeiraBrava, $24.6 \%$ in Funchal and $22.9 \%$ in Santa Cruz.

Table 2- Results on the level of exposure the questionnaire and experiences symptoms of PTSD, by groups, according to the municipality of residence.

\begin{tabular}{|l|c|c|c|c|}
\hline Variables & $\begin{array}{c}\text { Funchal } \\
(\mathrm{n}=350)^{*}\end{array}$ & $\begin{array}{c}\text { Santa } \\
\text { Cruz } \\
(\mathrm{n}=157)^{*}\end{array}$ & $\begin{array}{c}\text { Ribeira } \\
\text { Brava } \\
(\mathrm{n}=95)^{*}\end{array}$ & $p$ \\
\hline $\begin{array}{l}\text { Dissociative } \\
\text { responses to the } \\
\text { event } \\
\text { (QEPT, score })\end{array}$ & $\begin{array}{c}26.59 \\
(11.74)\end{array}$ & $\begin{array}{c}23.11 \\
(9.21)\end{array}$ & $\begin{array}{c}26.06 \\
(9.16)\end{array}$ & $<\mathbf{0 . 0 0 0 1}$ \\
\hline $\begin{array}{l}\text { Symptoms of } \\
\text { PTSD (EARAT, } \\
\text { score) }\end{array}$ & $\begin{array}{c}5.63 \\
(4.77)\end{array}$ & $\begin{array}{c}5.47 \\
(4.40)\end{array}$ & $\begin{array}{c}6.37 \\
(5.02)\end{array}$ & 0.307 \\
\hline SubscaleRelived & $\begin{array}{c}1.97 \\
(1.74)\end{array}$ & $\begin{array}{c}1.94 \\
(1.64)\end{array}$ & $\begin{array}{c}2.29 \\
(1.97)\end{array}$ & 0.232 \\
\hline SubscaleReply & 1.96 & 1.99 & 1.97 & 0.980 \\
\hline SubscaleExtende & $1.99)$ & $(1.81)$ & $(2.04)$ & $\mathbf{0 . 0 3 4}$ \\
\hline
\end{tabular}


d Response

$(1.74)$

$(1.62)$

$(1.61)$

*The values correspond to the mean and standard deviation.

The results of this study made it possible to verify that a percentage greater than $80 \%$ of the sample in General and, in particular, of each of the subsamples representing the three counties of RAM most affected by natural disaster of February 2010, 20 were exposed to significantsperi traumatic experiences. These results are superior to verified by Albuquerque et al. (2003) in the Portuguese population, which may be due to the impact of the disaster of February 2010.

In the case of sub-samples by municipality, the highest percentage of individuals exposed to peri traumatic experiences significant it was found in the sub-sample of Santa Cruz and the highest percentage of individuals with symptoms for diagnosis of PTSD was found in the sub-sample of Ribeira Brava. Since this study evaluates a late reply to this event ( 2 to 3 years after the disaster), these results can also express the result of psychosocial support interventions implemented in the different municipalities of the RAM, which were not analyzed in this research. Although in other studies, the prevalence of PTSD in the population exposed to natural disasters is between 5 and $10 \%$ (Galea et al., 2005), the prevalence of this psychopathology in the samples of the population studied in this research was between $22.9 \%$ and $32.4 \%$.Again, these results exceed those found in the study developed in a representative sample of the adult population of Portugal by Albuquerque et al. (2003), which identified a prevalence of PTSD in order of $7.9 \%$.

The results of the prevalence of PTSD of the present research are in the obtained in samples with direct victims of natural disasters, as concludes Galea et al. (2005) in a broad review of the literature. One explanation for such a prevalence of PTSD in a sample of the population, it may be due to the vast majority of adults residing in the municipalities of Funchal, Santa Cruz and Ribeira Brava that were direct victims of the disaster in question.

Some limitations of this research should be mentionedIt should be noted that the fact that the participants in this study were volunteers, may have influenced these results, as the most affected by the disaster may have expressed greater or lesser interest in participating. The long period of data collection and the remoteness of the date of occurrence of the traumatic event, determined by implementation difficulties, are limitations of this study, which can restrict the generalization to late responses to this event.

\section{CONCLUSIONS}

The results of this research show a significant impact of potential natural disaster of February 202010 in adult population resident in the municipalities of Funchal and Ribeira Brava and Santa Cruz. A high percentage of this sample identified exposure to peri traumatic experiences associated with dissociative responses potentially significant predictors of PTSD $(85.4 \%)$ and $25.4 \%$ presented criteria for diagnosing PTSD.The highest percentage of individuals exposed to peri traumatic experiences significant it was found in the sub-sample of Santa Cruz and the highest percentage of individuals with symptoms for diagnosis of PTSD was found in the sub-sample of RibeiraBravaAlthough the type of psychosocial response provided to this population had not been studied in this research, we believe that the results will be able to express the effect of interventions implemented.More research will be required to analyze this relationship and propose recommendations for intervention adapted to the population under study. However, the relevance of this scientific research and the clinical relevance of these results, see its usefulness in understanding the impact of the disaster of 20 February 2010 in the population resident in RAM and in the Organization of the necessary response to the support for victims of disasters, especially in terms of mental health. Additionally, the identification of individuals exposed to traumatic events significant through the QEPT and the diagnosis of PSTD by EARAT may be strategies to integrate the assessment made by the health professionals involved in the support of victims.

\section{REFERENCES}

1. Albuquerque, A.; Soares, C.; Jesus, P. \& Alves, C. (2003). Perturbação Pós-Traumática do Stress (PTSD): Avaliação da taxa de ocorrência na população adulta portuguesa. ActaMédica Portuguesa, 16, 309-320.

2. APA [American Psychiatric Association] (2013). Diagnostic and statistical manual of mental disorders (5th ed.).Washington: APA.

3. Galea, S., Nandi, A., \&Vlahov, D. (2005). The epidemiology of post-traumatic stress disorder after disasters. EpidemiologicReviews, 27, 78-91.

4. Maia, A., Guimarães, C., Magalhães, E., Capitão, L., Campos, M., \& Capela, S. (2006). Experiências adversas e funcionamento actual: um estudo com jovens portugueses. Actas do VI Congresso Nacional de Investigação em Psicologia. Vol XII. Associação Portuguesa de Psicologia, Portugal, p.54-73.

5. Maia, A., McIntyre, T., Pereira, G., \& Ribeiro, E. (2011). War exposure and Post-Traumatic Stress, as predictors of Portuguese colonial war veterans' physical health. Anxiety, Stress and Coping, 23, 1477-2205.

6. Maia, A., Moreira, S., \&Fernandes, E. (2009). Adaptação Portuguesa do Questionário de Experiências Dissociativas Peritraumáticas (QEDP) numa amostra de bombeiros. Revista de Psiquiatria Clínica; 36, 1-9.

7. McIntyre, T., \& Ventura, M. (1996). Escala de Avaliação da Resposta ao Acontecimento Traumático: Versão Adolescentes. In: Almeida, L.S., Araújo, S., Goncalves, M.M., Machado, C., Simões, M.R. (orgs.) Avaliação Psicológica: Formas e Contextos - IV (pp. 567-576). Braga: Associação dos Psicólogos Portugueses.

8. Neria, Y., Nandi, A, \&Galea, S. (2007). Post-traumatic stress disorder following disasters: a systematic review. PsychologicalMedicine, $1-14$. doi:10.1017/S0033291707001353

9. Pires, T. \& Maia, A. (2006). Acidentes rodoviários: incidência de PTSD nas vítimas directas. In: Leal I, Ribeiro JLP, Jesus SN (eds.). Actas do $6^{\circ}$ Congresso Nacional de Psicologia da Saúde (pp.811-818). Lisboa: Ispa Edições. 